\title{
Synthesis and Preliminary Evaluation of Phenyl 4-123I-Iodophenylcarbamate for Visualization of Cholinesterases Associated with Alzheimer Disease Pathology
}

\author{
Ian R. Macdonald ${ }^{1}$, G. Andrew Reid ${ }^{1}$, Ian R. Pottie ${ }^{2,3}$, Earl Martin², and Sultan Darvesh ${ }^{1,2,4}$ \\ ${ }^{I}$ Department of Medical Neuroscience, Dalhousie University, Halifax, Nova Scotia, Canada; ${ }^{2}$ Department of Chemistry and Physics, \\ Mount Saint Vincent University, Halifax, Nova Scotia, Canada; ${ }^{3}$ Department of Chemistry, Saint Mary's University, Halifax, Nova \\ Scotia, Canada; and ${ }^{4}$ Department of Medicine (Neurology and Geriatric Medicine), Dalhousie University, Halifax, Nova Scotia, Canada
}

Acetylcholinesterase and butyrylcholinesterase accumulate with brain $\beta$-amyloid $(A \beta)$ plaques in Alzheimer disease $(A D)$. The overall activity of acetylcholinesterase is found to decline in $A D$, whereas butyrylcholinesterase has been found to either increase or remain the same. Although some cognitively normal older adults also have $A \beta$ plaques within the brain, cholinesterase-associated plaques are generally less abundant in such individuals. Thus, brain imaging of cholinesterase activity associated with $A \beta$ plaques has the potential to distinguish $A D$ from cognitively normal older adults, with or without $A \beta$ accumulation, during life. Current $A \beta$ imaging agents are not able to provide this distinction. To address this unmet need, synthesis and evaluation of a cholinesterase-binding ligand, phenyl 4-123|-iodophenylcarbamate (123|-PIP), is described. Methods: Phenyl 4-iodophenylcarbamate was synthesized and evaluated for binding potency toward acetylcholinesterase and butyrylcholinesterase using enzyme kinetic analysis. This compound was subsequently rapidly radiolabeled with ${ }^{123} \mid$ and purified by high-performance liquid chromatography. Autoradiographic analyses were performed with 123/-PIP using postmortem orbitofrontal cortex from cognitively normal and $A D$ human brains. Comparisons were made with an $A \beta$ imaging agent, 2-(4'-dimethylaminophenyl)-6-123/-iodo-imidazo[1,2a]pyridine ( ${ }^{123} \mid-$ IMPY), in adjacent brain sections. Tissues were also stained for $A \beta$ and cholinesterase activity to visualize $A \beta$ plaque load for comparison with radioligand uptake. Results: Synthesized and purified PIP exhibited binding to cholinesterases. ${ }^{123}$ | was successfully incorporated into this ligand. ${ }^{123}$ I-PIP autoradiography with human tissue revealed accumulation of radioactivity only in $A D$ brain tissues in which $A \beta$ plaques had cholinesterase activity. ${ }^{123}$ /-IMPY accumulated in brain tissues with $A \beta$ plaques from both $A D$ and cognitively normal individuals. Conclusion: Radiolabeled ligands specific for cholinesterases have potential for use in neuroimaging AD plaques during life. The compound herein described, ${ }^{123}$ I-PIP, can detect cholinesterases associated with $A \beta$ plaques and can distinguish $A D$ brain tissues from those of cognitively normal older adults with $A \beta$ plaques. Imaging cholinesterase activity associated with $A \beta$ plaques in the living brain may contribute to the definitive diagnosis of $A D$ during life.

\footnotetext{
Received Jun. 11, 2015; revision accepted Oct. 21, 2015.

For correspondence or reprints contact: Sultan Darvesh, Rm. 1308, Camp Hill Veterans' Memorial, 5955 Veterans' Memorial Lane, Halifax, Nova Scotia, B3H 2E1, Canada.

E-mail: sultan.darvesh@dal.ca

Published online Nov. 5, 2015

COPYRIGHT (c) 2016 by the Society of Nuclear Medicine and Molecular Imaging, Inc.
}

Key Words: Alzheimer's disease; acetylcholinesterase; autoradiography; butyrylcholinesterase; carbamate; single photon emission computed tomography

J Nucl Med 2016; 57:297-302

DOI: 10.2967/jnumed.115.162032

\section{A} lzheimer disease (AD) is a neurodegenerative disorder and the most common cause of dementia. The prevalence of $\mathrm{AD}$ is predicted to dramatically rise over the next decades with concomitant increases in social and economic burdens (1). Efforts toward development of disease-modifying interventions for AD are hampered by a lack of early definitive diagnosis.

Currently, $\mathrm{AD}$ diagnosis is confirmed by postmortem brain visualization of $\beta$-amyloid $(A \beta)$ plaques and tau neurofibrillary tangles (2). Brain imaging methods aimed at $\mathrm{AD}$ diagnosis have emerged involving visualization of $A \beta$ plaques in the living brain. This approach has seen the development of agents such as 2-(4'dimethylaminophenyl)-6- ${ }^{123}$ I-iodo-imidazo[1,2-a]pyridine ( ${ }^{123}$ I-IMPY) (3), [N-methyl- ${ }^{11} \mathrm{C}-2-\left(4^{\prime}\right.$-methylaminophenyl)-6-hydroxybenzothiazole $\left({ }^{11} \mathrm{C}-\mathrm{PIB}\right)(4)$, and $(E)-4-\left(2-\left(6-\left(2-\left(2-\left(2-{ }^{18} \mathrm{~F}-\right.\right.\right.\right.\right.$ fluoroethoxy $)$ ethoxy $)$ ethoxy)pyridin-3-yl)vinyl)- $N$-methyl benzenamine ( ${ }^{18} \mathrm{~F}$-florbetapir) (5), among others, that bind to $A \beta$ plaques in vivo and are visualized using SPECT or PET. However, with agents that target $A \beta$ plaques, a major limitation is that a significant number of cognitively normal adults ( $10 \%$ at 50 y to $44 \%$ at 90 y) have such $\mathrm{A} \beta$ pathology $(6,7)$. This limits the utility of $A \beta$ plaque imaging agents alone for the premortem definitive diagnosis of $\mathrm{AD}$. Consequently, A $\beta$ imaging must be used in conjunction with clinical history and physical examinations as well as cognitive and neuropsychologic testing for the clinical diagnosis of $\mathrm{AD}(8)$. Therefore, the need is still great for biomarker development to aid in the diagnosis of AD.

Changes in the cholinergic system have been documented in $\mathrm{AD}$ (9). In particular there is loss of cholinergic neurons in the basal forebrain and other regions, thereby giving rise to many cognitive and behavioral symptoms (10). Two enzymes, acetylcholinesterase (AChE) and butyrylcholinesterase (BChE), hydrolyze acetylcholine and coregulate cholinergic neurotransmission in the brain (11). In the AD brain, AChE is significantly reduced (12); however, activity of BChE may increase (12) or remain the same $(13,14)$. Additionally, these enzymes associate with $\mathrm{A} \beta$ plaques and neurofibrillary tangles in $\operatorname{AD}(14,15)$. The significance of this association remains unclear but may be related to $A \beta$ plaque formation and 
maturation $(16,17)$. In addition, cholinesterases may associate predominantly with $\mathrm{AD}$ plaques and not those found in cognitively normal brain $(16,18,19)$. Therefore, plaque-associated AChE and $\mathrm{BChE}$ may represent specific markers for AD. Imaging of cholinesterases in brain $\mathrm{A} \beta$ plaques may aid in the diagnosis of $\mathrm{AD}$.

Several agents targeting AChE (20-23) and BChE (24-27) have been tested for human brain imaging of cholinesterase-associated AD pathology. However, focal visualization of cholinesterases associated with $\mathrm{AD}$ plaques has not been realized. Furthermore, an increase in radioligand uptake in regions typically associated with cholinesterase $\mathrm{AD}$ plaques has not been found in previous studies. For example, in vivo testing of $1{ }^{11} \mathrm{C}$-methyl-4-piperidinyl n-butyrate (27), a BChE-specific ester substrate radioligand, demonstrated decreased uptake in $\mathrm{AD}$ brain, contrary to the known histochemical and enzymatic isolation studies of this enzyme $(14,15)$. Cholinesterase ester substrates, such as $1-{ }^{11} \mathrm{C}$-methyl-4-piperidinyl $n$-butyrate, are rapidly metabolized by these enzymes. Thus, the ability to image cholinesterase activity with such agents relies on the metabolic trapping principle $(20,28)$ in which a radiolabeled hydrophilic product of enzyme catalysis gets trapped within the brain after ester hydrolysis. In contrast, carbamates have dual cholinesterase substrate/inhibitor properties in that they form a covalent bond with the enzymes that is long-lived (Fig. 1). This enzymatic trapping of a radiolabeled imaging agent (29) containing a carbamate functionality is expected to have a longer binding duration to cholinesterases, compared with ester substrates $(30,31)$. With the use of radiolabeled carbamate ligands, the temporal window for visualizing cholinesterase activity associated with $\mathrm{AD}$ pathology is potentially increased.

Herein are presented the synthesis, radiolabeling, and preliminary evaluation of phenyl 4-123 I-iodophenylcarbamate ( ${ }^{123}$ I-PIP, 3), which exhibits affinity toward cholinesterases in kinetic analysis. To demonstrate specificity toward cholinesterases associated with $\mathrm{A} \beta$ plaques in $\mathrm{AD}$ brains, 3 categories of brain tissues were compared, based on prior histochemical and immunohistochemical analysis, as well as clinical and neuropathologic information: cognitively normal without $A \beta$ plaques (normal/A $\beta-$ ), cognitively normal with $\mathrm{A} \beta$ plaques (normal/ $\mathrm{A} \beta+$ ), and $\mathrm{AD}$ orbitofrontal brain tissues. On the basis of previous observations (18), and confirmed in this preliminary study, cognitively normal individuals have less cholinesterase-associated $A \beta$ plaques than those with AD. It was demonstrated, using autoradiography, that ${ }^{123}$ I-PIP (3) is able to visualize cholinesterases in $\mathrm{A} \beta$ plaques in $\mathrm{AD}$ brain tissues. In addition, ${ }^{123} \mathrm{I}$-PIP (3), in contrast to the $A \beta$ imaging agent ${ }^{123}$ I-IMPY (Fig. 2), has the ability to distinguish $A \beta$ plaques in $\mathrm{AD}$ brain tissues from those in cognitively normal brains.

\section{MATERIALS AND METHODS}

\section{Synthesis and Radiolabeling}

Synthesis of ${ }^{123}$ I-PIP (Fig. 3). Phenol (1.021 g, $10.85 \mathrm{mmol}$ ) was dissolved in dry toluene $(2 \mathrm{~mL})$ under argon atmosphere to which was added iodophenylisocyanate $(2.658 \mathrm{~g}, 10.85 \mathrm{mmol})$, dissolved in dry toluene $(13 \mathrm{~mL})$. This mixture was refluxed for $5 \mathrm{~h}$. The resulting precipitate was hot gravity filtered to collect the resulting white crystalline product $(1.983 \mathrm{~g}, 54 \%)$. Phenyl 4-iodophenylcarbamate $(1,0.200 \mathrm{~g}, 0.59 \mathrm{mmol})$ was suspended in dry $\mathrm{CH}_{2} \mathrm{Cl}_{2}(10 \mathrm{~mL})$ under argon atmosphere. To this was added triethylamine $(0.18 \mathrm{~mL}, 1.3 \mathrm{mmol})$ followed by triisopropylsilyl triflate $(0.32 \mathrm{~mL}, 1.2 \mathrm{mmol})$. This solution was then added to tetrakis(triphenylphosphine)palladium(0) (0.026 g, $0.023 \mathrm{mmol})$ to which was added hexabutylditin $(0.60 \mathrm{~mL}, 1.2 \mathrm{mmol})$. The reaction mixture was refluxed for $16 \mathrm{~h}$, cooled to room temperature,

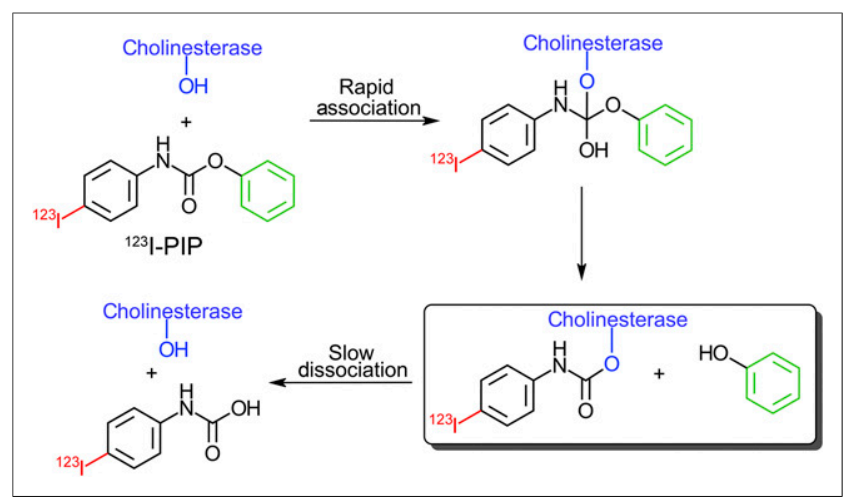

FIGURE 1. Schematic representation of interaction between cholinesterase catalytic serine and ${ }^{123}$ I-PIP showing slow dissociation of covalent intermediate containing ${ }^{123}$, a step occurring rapidly with ester substrates.

and purified by silica gel flash chromatography (1:9 ethyl acetate/hexanes) to yield the desired compound as a white solid $(0.147 \mathrm{~g}, 50 \%)$. To a solution $(9 \mu \mathrm{L})$ of $\mathrm{Na}^{123} \mathrm{I}(64.42 \mathrm{MBq})$ in $0.1 \mathrm{M} \mathrm{NaOH}_{(\mathrm{aq})}(9.0 \times$ $10^{-7} \mathrm{~mol}$ ) (MDS Nordion) was added $0.1 \mathrm{M} \mathrm{HCl}(18 \mu \mathrm{L}, 1.8 \times$ $\left.10^{-6} \mathrm{~mol}\right)$ to neutralize the hydroxide. Phenyl 4-tributylstannylphenylcarbamate $\left(2,50 \mu \mathrm{L}, 4.0 \times 10^{-7} \mathrm{~mol}\right)$ was added to the solution followed by $N$-chlorosuccinimide $\left(28 \mu \mathrm{L}, 8.4 \times 10^{-8} \mathrm{~mol}\right)$, both of which were dissolved in $\mathrm{MeOH}$. The reaction was allowed to proceed for $15 \mathrm{~min}$ at room temperature; then $0.1 \mathrm{M} \mathrm{NaHCO}_{3}(27 \mu \mathrm{L}, 2.7 \times$ $10^{-3} \mathrm{~mol}$ ) was added. The reaction mixture was purified by highperformance liquid chromatography, using a SemiPrep system with a Zorbax Eclipse XDB-C18, $4.6 \times 150 \mathrm{~mm}, 5-\mu \mathrm{m}$ column (Agilent Technologies) and $1.0 \mathrm{~mL} / \mathrm{min}$ of $80 \% \mathrm{MeOH}: 20 \% \mathrm{dH}_{2} \mathrm{O}$ eluent. Fractions were collected every $20 \mathrm{~s}$ for $15 \mathrm{~min}$ with a RediFrac fraction collector (Pharmacia). Retention times were determined using the corresponding cold PIP (1) as a nonradioactive standard (3.9 min). Collected fractions that contained pure product were combined and acidified with $\mathrm{HCl}$ $(0.1 \mathrm{M}, 1 \mathrm{~mL})$, and the solvent was removed under a stream of $\mathrm{N}_{2}$ gas with low heat to yield the desired radiolabeled compound as a residue (radiochemical yield, $87 \%$; radiochemical purity, $>96 \%$; specific activity, $>3,000 \mathrm{GBq} / \mu \mathrm{mol})$. The residue was dissolved in $0.1 \mathrm{M}$ maleate buffer, $\mathrm{pH} 7.4$, for incubation with brain tissues. The supplemental data (Supplemental Figs. 1-8, available at http://tech.snmjournals.org) provide analytic data for compounds synthesized (Fig. 3).

Synthesis of ${ }^{123}$ I-IMPY. ${ }^{123}$ I-IMPY was synthesized according to a previously published procedure, and the analytic data were consistent with the structure of the compound as described (3).

\section{Esterase Activity Assay}

Cholinesterase activity was determined using a modification (32) of Ellman's spectrophotometric method (33). To test for interaction of enzyme with PIP (1; Fig. 2), enzyme activity was determined after various time intervals of incubation with $0.033 \mathrm{mM}$ PIP, a concentration that avoided complete deactivation of enzyme before steady-state conditions were attained. Second-order association constants $\left(k_{\mathrm{a}}\right.$ values) were determined as previously described (34).

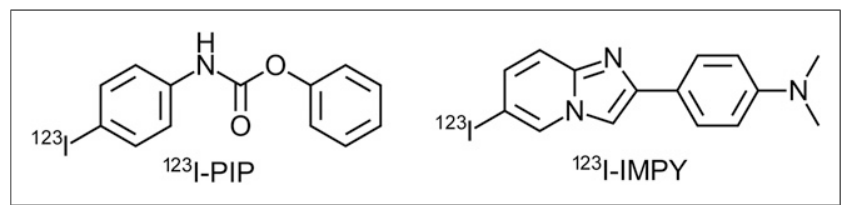

FIGURE 2. Structures of cholinesterase imaging agent ${ }^{123}$ I-PIP and $\beta$-amyloid imaging agent ${ }^{123}$-IMPY. 


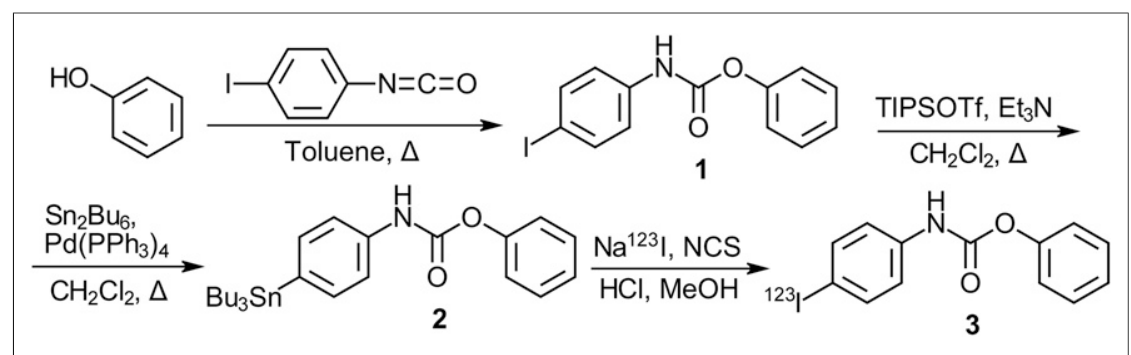

FIGURE 3. Synthesis of PIP (1), corresponding tributyltin precursor (2), and ${ }^{123}$-radiolabeled product $\left(3,{ }^{123}\right.$-PIP). $\mathrm{Et}_{3} \mathrm{~N}=$ triethylamine; $\mathrm{NCS}=\mathrm{N}$-chlorosuccinimide; $\mathrm{Pd}\left(\mathrm{PPh}_{3}\right)_{4}=$ tetrakis (triphenylphosphine)palladium(0); $\mathrm{Sn}_{2} \mathrm{Bu}_{6}=$ hexabutylditin; TIPSOTf $=$ triisopropylsilyl trifluoromethanesulfonate.

\section{Tissue Autoradiography}

For this initial evaluation of ${ }^{123}$ I-PIP (3), the human orbitofrontal cortex was studied, supported by corresponding clinical and neuropathologic information for each brain (Supplemental Table 1). Brain tissue and related information were provided by the Maritime Brain Tissue Bank, after approval from the Nova Scotia Health Research Ethics Board. Cases were designated as $\mathrm{AD}(n=10,83 \pm 12$ y old $)$, normal $/ \mathrm{A} \beta+(n=2$; age, 63 and $86 \mathrm{y})$, and normal/A $\beta-(n=3$; age, 55,63 , and $71 \mathrm{y}$ ) based on neuropathologic diagnosis and the presence or absence of $A \beta$ plaques. For analysis of ${ }^{123}$ I-PIP, AD, nor$\mathrm{mal} / \mathrm{A} \beta+$, and normal/A $\beta-$ sections $(n=74,11$, and 30 , respectively) were radiolabeled. Brains were immersion-fixed in $10 \%$ formalin in $0.1 \mathrm{M}$ phosphate buffer (PB) $(\mathrm{pH} 7.4)$ and cut in 1- to $2-\mathrm{cm}$ coronal slabs. These slabs were cryoprotected by immersion in increasing concentrations of sucrose, ranging from $10 \%$ to $40 \%$ in $0.1 \mathrm{M} \mathrm{PB}(\mathrm{pH} 7.4)$ and stored in $40 \%$ sucrose in $0.1 \mathrm{M} \mathrm{PB}(\mathrm{pH} 7.4)$ with $0.6 \%$ sodium azide until used. Blocks of tissue from the orbitofrontal cortex were cut on a Leica SM2000R microtome with Physitemp freezing stage and BFS-30TC controller in 50- $\mu \mathrm{m}$ serial sections. Sections were stored in $40 \%$ sucrose in $0.1 \mathrm{M} \mathrm{PB}$ ( $\mathrm{pH} 7.4$ ) at $-20^{\circ} \mathrm{C}$ until used. Before use, sections were thawed and rinsed in $0.1 \mathrm{M}$ maleate buffer ( $\mathrm{pH}$ 7.4). To each section in $900 \mu \mathrm{L}$ of $0.1 \mathrm{M}$ maleate buffer $\mathrm{pH} 7.4$ was added $100 \mu \mathrm{L}$ of maleate buffer $(\mathrm{pH} 7.4)$ containing ${ }^{123}$ I-PIP (3, $\left.1.1 \mathrm{MBq}\right)$ and the tissue incubated for up to $3 \mathrm{~h}$ with gentle agitation. The tissue was then rinsed twice for 1 min each in distilled water, mounted, dried on a slide warmer, and exposed to a high-resolution phosphor imaging screen (GE Healthcare). The screen was scanned with a Typhoon 9400 imager (GE Healthcare) to produce the autoradiogram. Images were saved using ImageQuant (GE Healthcare) and contrast-adjusted so the background from different images matched with Adobe Photoshop CS5.

Autoradiography with ${ }^{123}$ I-IMPY was performed using a modification of a published procedure (3). Sections to be incubated with ${ }^{123}$ I-IMPY were thawed, washed in maleate buffer ( $\mathrm{pH} 7.4$ ), mounted, and dried. The sections were rehydrated in maleate buffer $(\mathrm{pH} 7.4$ ) for $3 \mathrm{~min}$ and incubated in $35 \mathrm{~mL}$ of maleate buffer ( $\mathrm{pH}$ 7.4), with $560 \mu \mathrm{L}$ of $0.1 \%$ bovine serum albumin in maleate buffer (pH 7.4) containing ${ }^{123}$ I-IMPY (1.7 MBq/per section). The tissue was incubated for $1 \mathrm{~h}$ with gentle agitation and subsequently rinsed for 2 min in saturated $\mathrm{Li}_{2} \mathrm{CO}_{3}$ in $50 \% \mathrm{EtOH}_{(\mathrm{aq})}, 2$ min in $50 \%$ $\mathrm{EtOH}_{(\mathrm{aq})}$, and $30 \mathrm{~s}$ in distilled water. The sections were dried and exposed to the phosphor imaging screen and images generated as described above.

\section{Histochemistry}

Brain tissue sections adjacent to those used for autoradiography were stained and analyzed for cholinesterases and thioflavin-S using previously described methods $(14,17)$.

\section{RESULTS}

\section{Synthesis and Radiolabeling}

Phenyl 4-iodophenylcarbamate (PIP, 1) was synthesized from phenol and 4iodophenylisocyanate (Fig. 3). Radiolabeling was performed in 2 steps; the initial step involved protection of the carbamate functionality with a triisopropylsilyl group followed by generation of a tributyltin intermediate, deprotection, and subsequent introduction of ${ }^{123} \mathrm{I}$.

Synthesis of IMPY followed a previously published procedure (3). The corresponding tributyl tin intermediate was generated and ${ }^{123}$ I introduced.

${ }^{123}$ I-PIP (3) and ${ }^{123}$ I-IMPY were both purified by high-performance liquid chromatography and recovered in high yield, $87 \%$ and $71 \%$, and purity, $>96 \%$ and $>99 \%$, respectively. Radiolabeling of ${ }^{123}$ I-PIP (3) and ${ }^{123}$ I-IMPY could be performed efficiently and quickly within $1 \mathrm{~h}$.

\section{Cholinesterase Kinetics}

PIP (1; Fig. 3) interacted with both AChE and BChE at a concentration $(0.033 \mathrm{mM})$ that avoided complete deactivation of the enzymes. PIP (1) demonstrated time-dependent association with both $\mathrm{AChE}$ and $\mathrm{BChE}$, quantified as the second-order association constants $\left(k_{\mathrm{a}}\right)$. Interaction of AChE with PIP (1; Supplemental Fig. 1) was more rapid $\left(k_{\mathrm{a}}: 1.56 \pm 0.18 \times 10^{4} \mathrm{M}^{-1} \mathrm{~min}^{-1}\right)$ than $\mathrm{BChE}\left(k_{\mathrm{a}}\right.$ : $\left.3.47 \pm 0.82 \times 10^{2} \mathrm{M}^{-1} \mathrm{~min}^{-1}\right)$.

\section{Human Tissue Autoradiography}

In an overview analysis (Fig. 4) and in all AD cases (74 sections total) radioactivity was observed to accumulate in the orbitofrontal cortex when tissue was exposed to ${ }^{123}$ I-PIP (3) or ${ }^{123} \mathrm{I}$-IMPY (Fig. 4 , top). Brain tissue from normal/A $\beta+$ cases revealed radiolabel deposition from ${ }^{123}$ I-IMPY but no comparable accumulation from ${ }^{123}$ I-PIP (3) in 11 sections of the orbitofrontal cortex of these brains studied (Fig. 4, middle). No radiolabel accumulation from either agent occurred in the orbitofrontal cortex of 30 sections from normal/A $\beta$ - cases (Fig. 4, bottom).

A more detailed analysis of $A \beta$ plaque visualization compared autoradiography with histochemical techniques for detecting fibrillar $\mathrm{A} \beta$ plaques using thioflavin-S and cholinesterase activity in the orbitofrontal cortex region of the brain (Fig. 5). In AD brain tissue, distinct $A \beta$ plaques were visualized with all methods used for analysis. Normal/A $\beta+$ brain tissue provided $A \beta$ plaque visualization only with thioflavin-S and ${ }^{123}$ I-IMPY. With normal/A $\beta-$ brain tissue, no $\mathrm{A} \beta$ plaques were detected by any of the methods used. Thus, visualization of cholinesterase activity in association with $A \beta$ plaques, whether by histochemical or radiochemical means, is able to distinguish $\mathrm{AD}$ pathology from $\mathrm{A} \beta$ plaques in normal brain tissue.

\section{DISCUSSION}

PIP synthesis (1; Fig. 3) was achieved in a 1-step reaction. ${ }^{123} \mathrm{I}-$ PIP radiolabeling (3; Fig. 3) involved protection of PIP (1) with a triisopropylsilyl group and replacement of iodine by a tributyltin by reaction with hexabutylditin in the presence of palladium catalyst. In contrast to a comparable ester-tributyltin intermediate synthesis (35), attempts at conversion of PIP (1) to the tributyltin intermediate without silyl protection were unsuccessful, suggesting the unprotected carbamate functionality interferes with stannylation 


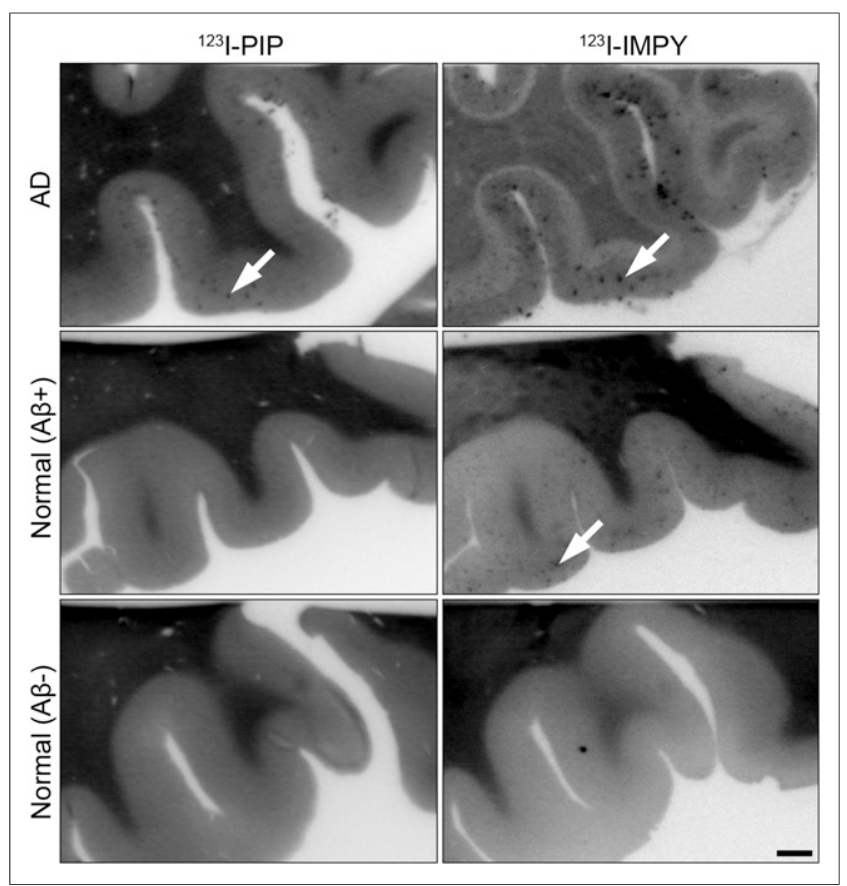

FIGURE 4. Photomicrographs of representative human orbitofrontal cortex sections from normal/A $\beta-$, normal/A $\beta+$, and $A D$ human orbitofrontal cortex showing in vitro autoradiography with ${ }^{123}$ I-PIP (3) and ${ }^{123}$ I-IMPY. In all AD brain tissue, sections labeled with ${ }^{123}$ I-IMPY and ${ }^{123}$ I-PIP $(n=74)$ visualized $A \beta$ plaques. $A \beta$ plaques in normal/ $A \beta+$ sections were visualized with ${ }^{123}$ |-IMPY but were not labeled with 123/-PIP $(n=11)$. Sections of cortex from normal/A $\beta$ - did not show accumulation of either ${ }^{123}$ I-PIP $(n=30)$ or ${ }^{123}$ I-IMPY. ${ }^{123}$ I-PIP (3) demonstrates selectivity for detection of $A \beta$ plaques in $A D$ brain and not those in cognitively normal brain. Arrows indicate $A \beta$ plaques. Scale bar $=1 \mathrm{~mm}$.

of the iodophenyl moiety of PIP (1). The silyl carbamate protecting group was readily removed during the workup. Triisopropylsilyl protection has been reported to protect the nitrogen of carbamates, normally requiring concentrated acid for removal (36). Facile removal of the silyl protecting group from PIP (1) may be due to steric effects of neighboring phenyl rings. The stannylated product was purified from reagents and starting material by high-performance liquid chromatography. After stannylation, incorporation of ${ }^{123} \mathrm{I}$ occurred readily at room temperature in the presence of $\mathrm{N}$-chlorosuccinimide, and the product was purified by high-performance liquid chromatography.

Conversion of IMPY to the tributyltin intermediate was achieved using a procedure similar to that used for PIP (1) and previous ester molecules (35). However, subsequent attempts to incorporate ${ }^{123} \mathrm{I}$ into IMPY using $N$-chlorosuccinimide as a free radical initiator were unsuccessful. This may be due to the lone pair of electrons on nitrogen atoms in IMPY that are not involved in active $\pi$-bonding, thus are available to interfere with free radical generation. The use of hydrogen peroxide to initiate the reaction, as previously described for ${ }^{123}$ I-IMPY synthesis (3), yielded the desired radiolabeled product.

PIP (1) interacted with both $\mathrm{AChE}$ and $\mathrm{BChE}$ and, similar to most other carbamates $(34,37)$, produced a time-dependent association with these enzymes, suggesting the formation of a covalently bonded carbamoylated enzyme intermediate. Carbamates are known to form covalent intermediates with the catalytic group of serine hydrolases $(30,31)$. Several factors can influence selectivity for one cholinesterase over another, including the size of the carbamate-containing molecule relative to each enzyme's active site gorge (30) and interactions with functional groups within the gorge (37). Most previously tested cholinesterase imaging agents are esters and hydrolyzed rapidly by $\mathrm{AChE}$ and $\mathrm{BChE}$. Such rapid hydrolysis may be detrimental for in vivo imaging of this enzyme activity by permitting diffusion of the product containing the radiolabel away from the target enzyme. In contrast, time-dependent association of cholinesterases with PIP (1) indicates that radioactivity is bound with enzyme significantly longer than with ester substrates. This longer-lived association of PIP (1) components with cholinesterases is expected to afford an extended window for visualization of this enzyme activity.

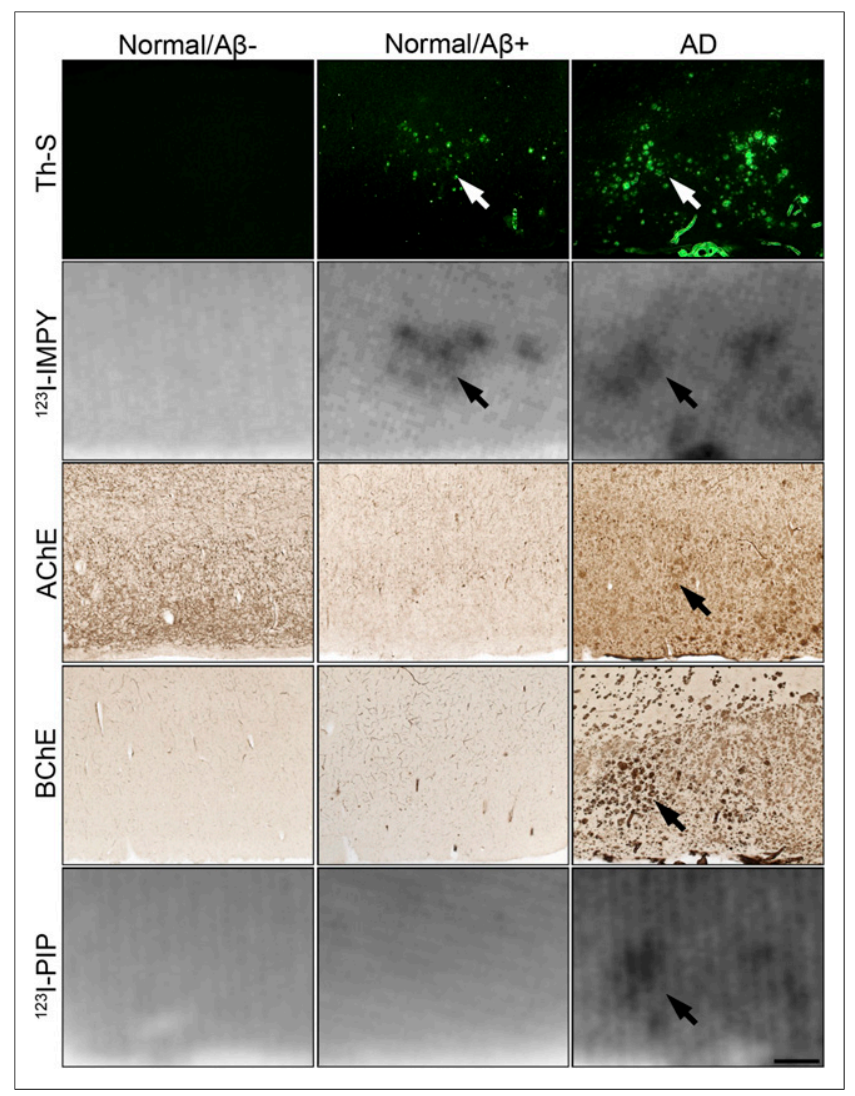

FIGURE 5. Photomicrographs of representative human orbitofrontal cortex sections from normal/A $\beta-;$ normal/A $\beta+;$ and $A D$ cases showing histofluorescent staining with thioflavin-S (Th-S), autoradiography with 123I-IMPY, histochemical staining for AChE and BChE, and autoradiography with ${ }^{123}$ I-PIP (3). Accumulation of ${ }^{123}$ I-IMPY in cortex corresponded to Th-S-positive $A \beta$ deposits in brain tissues from both $A D$ and normal/A $\beta+$ individuals. Brain tissues from normal/A $\beta$ - individuals did not show cortical accumulation of ${ }^{123}$-IMPY. Autoradiography of $A \beta$ deposition with ${ }^{123}$ I-IMPY is not able to distinguish AD from normal/ $\mathrm{A} \beta+$. Accumulation of ${ }^{123} \mathrm{I}$-PIP (3) in sections of orbitofrontal cortex $(n=74)$ corresponded to BChE, AChE, and Th-S-positive A $\beta$ deposits in $A D$ only. Normal/A $\beta$ + tissues were positive for Th-S; however, BChE and AChE activity was not associated with these structures and ${ }^{123} \mathrm{I}-\mathrm{PIP}$ (3) also did not accumulate in these sections $(n=11)$. Similarly, normal/ $A \beta$ - tissues were devoid of plaque-associated cholinesterase activity, and ${ }^{123}$ I-PIP (3) did not accumulate in these sections $(n=30)$. Autoradiography of cholinesterase-associated $A \beta$ deposition with ${ }^{123}$ I-PIP (3) is able to distinguish $A D$ from normal/A $\beta+$. Arrows indicate plaques visualized using described methods. Scale bar $=500 \mu \mathrm{m}$. 
Kuhl et al. reported decreased AChE and BChE activity in the brain of AD patients (27). However, this result may reflect synaptic cholinesterase levels as opposed to the plaque-associated cholinesterases thought to contribute to the in vitro and isolation measurements of these enzymes $(14,15)$. Other potential imaging agents evaluated for cholinesterases have also had difficulty in reflecting histochemical and isolation enzymatic levels, possibly due to complex kinetics and low specificity (38). The present study specifically aimed to visualize plaque-associated cholinesterases in $\mathrm{AD}$ brain tissue, a result that has not been realized with previously tested cholinesterase imaging agents.

This study used postmortem brain tissue from 3 clinical and neuropathologic classifications, $\mathrm{AD}$, normal/A $\beta+$, and normal/ $\mathrm{A} \beta-$ (Fig. 4). Autoradiography of these tissues demonstrated that ${ }^{123}$ I-IMPY detects, without discrimination, thioflavin-S-positive deposits of $\mathrm{A} \beta$ in both $\mathrm{AD}$ and normal/A $\beta+$ brains (Figs. 4 and 5). In contrast, ${ }^{123}$ I-PIP (3) accumulated only in regions of thioflavin$S$-positive $\mathrm{A} \beta$ plaques in $\mathrm{AD}$ and not normal/A $\beta+$ brain tissues (Figs. 4 and 5). Furthermore, these focal ${ }^{123}$ I-PIP (3) accumulations correspond to areas of histochemically detected cholinesterase activity associated with $A \beta$ plaque pathology (Fig. 5). Although the sample of brains used in this preliminary study is small, the observations are consistent with other published data showing that $\mathrm{BChE}$ can distinguish plaques of aging from those of dementia (18). Several additional studies are required to further validate plaque-associated cholinesterase imaging for the diagnosis of AD. Because of the limited number of brain tissues analyzed in the current study, a larger postmortem cohort with examination of various brain regions will be required to further assess the capability of such cholinesterase carbamate imaging agents to distinguish between cognitively normal and AD brains. In addition, cholinesterases are found in high concentrations in the plasma, thus, potentially presenting a challenge for the intravenous administration of such cholinesterase imaging agents to reach the brain for in vivo assessment. However, in this respect, studies of BChE imaging agents to date $(27,35)$ suggest that cholinesterase radiopharmaceuticals can be delivered to the brain in sufficient quantity for imaging enzyme activity. SPECT imaging of transgenic $\mathrm{AD}$ mice may further elucidate the in vivo characteristics of this cholinesterase imaging agent.

In the present study, ${ }^{123}$ I-PIP (3) recapitulated the histochemical association of cholinesterases with $\mathrm{A} \beta$ plaques and, in a small postmortem sample, distinguished AD brain pathology from cognitively normal brains containing $A \beta$ plaques, based on the presence or absence of cholinesterase activity.

\section{CONCLUSION}

The cholinesterases $\mathrm{AChE}$ and $\mathrm{BChE}$ are associated with $\mathrm{A} \beta$ plaques in the $\mathrm{AD}$ brain and are potential imaging targets for the diagnosis of this disease. We have described the synthesis and radiolabeling of the cholinesterase ligand ${ }^{123}$ I-PIP, which binds to both enzymes. This radioimaging agent visualized cholinesterase activity associated with $\mathrm{A} \beta$ plaques in human $\mathrm{AD}$ brain tissues. In contrast, this imaging agent does not detect $A \beta$ plaques in cognitively normal brain tissue in which associated cholinesterase activity is minimal. Thus, in this preliminary study ${ }^{123}$ I-PIP was able to differentiate $\mathrm{AD}$ brain from normal/A $\beta+$. Imaging cholinesterase-associated $A \beta$ pathology is a significant advance for this biomarker and is a promising approach toward the definitive diagnosis of $\mathrm{AD}$ during life.

\section{DISCLOSURE}

The costs of publication of this article were defrayed in part by the payment of page charges. Therefore, and solely to indicate this fact, this article is hereby marked "advertisement" in accordance with 18 USC section 1734 . This research was supported by the Canadian Institutes of Health Research (MOP-82798, RNS-117795, MOP-119343), Capital Health Research Fund, Nova Scotia Health Research Foundation (MED-MAT-2011-7512), Faculty and Department of Medicine of Dalhousie University, Natural Sciences and Engineering Research Council of Canada, Killam Trusts, Innovacorp, Dalhousie Medical Research Foundation, Gunn Family Research Prize, the Dalhousie Medical Research Foundation Irene MacDonald Sobey Endowed Chair in Curative Approaches to Alzheimer's Disease, and Ms. Sadie MacLeod. Sultan Darvesh is a scientific cofounder and stockholder in Treventis Corporation, a biotech company focused on development of diagnostic and therapeutic agents for Alzheimer's disease. Sultan Darvesh, Ian R. Macdonald, Ian R. Pottie, and Earl Martin are listed as inventors on patents related to this work, and these patents are assigned to Treventis Corporation. No other potential conflict of interest relevant to this article was reported.

\section{ACKNOWLEDGMENT}

We thank Sean Jay Kelly for his technical assistance.

\section{REFERENCES}

1. World Health Organization and Alzheimer's Disease International. Dementia: A Public Health Priority. Geneva, Switzerland: World Health Organization; 2012.

2. Hyman BT, Trojanowski JQ. Consensus recommendations for the postmortem diagnosis of Alzheimer disease from the National Institute on Aging and the Reagan Institute Working Group on diagnostic criteria for the neuropathological assessment of Alzheimer disease. J Neuropathol Exp Neurol. 1997;56:10951097.

3. Zhuang ZP, Kung MP, Wilson A, et al. Structure-activity relationship of imidazo [1,2-a]pyridines as ligands for detecting beta-amyloid plaques in the brain. J Med Chem. 2003;46:237-243.

4. Klunk WE, Engler H, Nordberg A, et al. Imaging brain amyloid in Alzheimer's disease with Pittsburgh compound-B. Ann Neurol. 2004;55:306-319.

5. Clark CM, Pontecorvo MJ, Beach TG, et al. Cerebral PET with florbetapir compared with neuropathology at autopsy for detection of neuritic amyloid-beta plaques: a prospective cohort study. Lancet Neurol. 2012;11:669-678.

6. Jansen WJ, Ossenkoppele R, Knol DL, et al. Prevalence of cerebral amyloid pathology in persons without dementia: a meta-analysis. JAMA. 2015;313:1924-1938.

7. Mortimer JA. The Nun Study: risk factors for pathology and clinical-pathologic correlations. Curr Alzheimer Res. 2012;9:621-627.

8. Johnson KA, Minoshima S, Bohnen NI, et al. Appropriate use criteria for amyloid PET: a report of the Amyloid Imaging Task Force, the Society of Nuclear Medicine and Molecular Imaging, and the Alzheimer's Association. J Nucl Med. 2013;54:476-490.

9. Davies P, Maloney AJ. Selective loss of central cholinergic neurons in Alzheimer's disease. Lancet. 1976;2:1403.

10. Pinto T, Lanctôt KL, Herrmann N. Revisiting the cholinergic hypothesis of behavioral and psychological symptoms in dementia of the Alzheimer's type. Ageing Res Rev. 2011;10:404-412.

11. Darvesh S, Hopkins DA, Geula C. Neurobiology of butyrylcholinesterase. Nat Rev Neurosci. 2003;4:131-138.

12. Perry EK, Perry RH, Blessed G, Tomlinson BE. Changes in brain cholinesterases in senile dementia of Alzheimer type. Neuropathol Appl Neurobiol. 1978;4:273-277.

13. Atack JR, Perry EK, Bonham JR, Candy JM, Perry RH. Molecular forms of acetylcholinesterase and butyrylcholinesterase in the aged human central nervous system. J Neurochem. 1986;47:263-277.

14. Darvesh S, Reid AG, Martin E. Biochemical and histochemical comparison of cholinesterases in normal and Alzheimer brain tissues. Curr Alzheimer Res. 2010;7:386-400. 
15. Geula C, Mesulam MM. Cholinesterases and the pathology of Alzheimer disease. Alzheimer Dis Assoc Disord. 1995;9(suppl 2):23-28.

16. Guillozet AL, Smiley JF, Mash DC, Mesulam MM. Butyrylcholinesterase in the life cycle of amyloid plaques. Ann Neurol. 1997;42:909-918.

17. Reid GA, Darvesh S. Butyrylcholinesterase-knockout reduces brain deposition of fibrillar beta-amyloid in an Alzheimer mouse model. Neuroscience. 2015;298:424-435.

18. Mesulam MM, Geula C. Butyrylcholinesterase reactivity differentiates the amyloid plaques of aging from those of dementia. Ann Neurol. 1994;36:722-727.

19. Geula C, Darvesh S. Butyrylcholinesterase, cholinergic neurotransmission and the pathology of Alzheimer's disease. Drugs Today (Barc). 2004;40:711-721.

20. Irie T, Fukushi K, Akimoto Y, Tamagami H, Nozaki T. Design and evaluation of radioactive acetylcholine analogs for mapping brain acetylcholinesterase in vivo. Nucl Med Biol. 1994;21:801-808.

21. Kilbourn MR, Snyder SE, Sherman PS, Kuhl DE. In vivo studies of acetylcholinesterase activity using a labeled substrate, $N$ - $\left[{ }^{11} \mathrm{C}\right]$ methylpiperdin-4-yl propionate ([11 C]PMP). Synapse. 1996;22:123-131.

22. Irie T, Fukushi K, Namba H, et al. Brain acetylcholinesterase activity: validation of a PET tracer in a rat model of Alzheimer's disease. J Nucl Med. 1996;37:649-655.

23. Snyder SE, Tluczek L, Jewett DM, Nguyen TB, Kuhl DE, Kilbourn MR. Synthesis of $1-\left[{ }^{11} \mathrm{C}\right]$ methylpiperidin-4-yl propionate $\left(\left[{ }^{11} \mathrm{C}\right] \mathrm{PMP}\right)$ for in vivo measurements of acetylcholinesterase activity. Nucl Med Biol. 1998;25:751-754.

24. Kikuchi T, Fukushi K, Ikota N, et al. T. Synthesis of piperidinyl and pyrrolidinyl butyrates for potential in vivo measurement of cerebral butyrylcholinesterase activity. J Labelled Comp Radiopharm. 2001;44:31-41.

25. Snyder SE, Gunupudi N, Sherman PS, et al. Radiolabeled cholinesterase substrates: in vitro methods for determining structure-activity relationships and identification of a positron emission tomography radiopharmaceutical for in vivo measurement of butyrylcholinesterase activity. J Cereb Blood Flow Metab. 2001;21: $132-143$.

26. Kikuchi T, Zhang MR, Ikota $\mathrm{N}$, et al. $N$ - $\left[{ }^{18} \mathrm{~F}\right]$ fluoroethylpiperidin-4-ylmethyl butyrate: a novel radiotracer for quantifying brain butyrylcholinesterase activity by positron emission tomography. Bioorg Med Chem Lett. 2004;14:1927-1930.
27. Kuhl DE, Koeppe RA, Snyder SE, Minoshima S, Frey KA, Kilbourn MR. In vivo butyrylcholinesterase activity is not increased in Alzheimer's disease synapses. Ann Neurol. 2006;59:13-20.

28. Kikuchi T, Okamura T, Fukushi K, et al. Cerebral acetylcholinesterase imaging: development of the radioprobes. Curr Top Med Chem. 2007;7:1790-1799.

29. Darvesh S. Butyrylcholinesterase radioligands to image Alzheimer's disease brain. Chem Biol Interact. 2013;203:354-357.

30. Aldridge WN, Reiner E. Enzyme Inhibitors as Substrates: Interactions of Esterases with Esters of Organophosphorus and Carbamic Acids. Amsterdam, The Netherlands: North-Holland Pub. Co.; 1972.

31. Schopfer LM, Lockridge O. Analytical approaches for monitoring exposure to organophosphorus and carbamate agents through analysis of protein adducts. Drug Test Anal. 2012;4:246-261.

32. Darvesh S, Kumar R, Roberts S, Walsh R, Martin E. Butyrylcholinesterasemediated enhancement of the enzymatic activity of trypsin. Cell Mol Neurobiol. 2001;21:285-296.

33. Ellman GL, Courtney KD, Andres V Jr, Feather-Stone RM. A new and rapid colorimetric determination of acetylcholinesterase activity. Biochem Pharmacol. 1961;7:88-95.

34. Darvesh S, Walsh R, Kumar R, et al. Inhibition of human cholinesterases by drugs used to treat Alzheimer disease. Alzheimer Dis Assoc Disord. 2003;17:117126.

35. Macdonald IR, Reid GA, Joy EE, et al. Synthesis and preliminary evaluation of piperidinyl and pyrrolidinyl iodobenzoates as imaging agents for butyrylcholinesterase. Mol Imaging Biol. 2011;13:1250-1261.

36. Roby J, Voyer N. Protection of a protecting group: preparation of stable N-silylated t-butyl carbamates. Tetrahedron Lett. 1997;38:191-194.

37. Darvesh S, Darvesh KV, McDonald RS, et al. Carbamates with differential mechanism of inhibition toward acetylcholinesterase and butyrylcholinesterase. J Med Chem. 2008;51:4200-4212.

38. Kikuchi T, Okamura T, Zhang MR, Irie T. PET probes for imaging brain acetylcholinesterase. J Labelled Comp Radiopharm. 2013;56:172-179. 